\title{
Pengembangan Model Pembelajaran Matematika SD \\ Berbasis Permainan Tradisional Indonesia dan Pendekatan Matematika Realistik
}

\author{
Yohana Setiawan \\ yohana.setiawan@uksw.edu \\ Pendidikan Guru Sekolah Dasar, FKIP, Universitas Kristen Satya Wacana \\ Developing Primary School Mathematics Learning Model Based On \\ Indonesian Traditional Game And Realistic Mathematics Approach
}

\begin{abstract}
This research was the first four parts of the Borg and Gall version of RnD research, (1) preliminary research and studies, (2) research planning, (3) initial product development, and (4) limited field testing. The purpose of this study is to explain the importance of using traditional games in teaching mathematics in elementary schools using a realistic mathematical approach. The method used is qualitative. Data obtained through interviews and teacher response scales. The subjects of this study were 15 elementary school teachers teaching elementary mathematics in Salatiga which were selected by purposive sampling technique. The results of this study is the steps to develop traditional games with a realistic mathematical approach in elementary mathematics learning.
\end{abstract}

Keywords: Matematika SD, Matematika Realistik, Permainan Tradisional

Received date: 5 Desember 2019

Article Info

Revised date: 7 Januari 2020

Accepted date: 21 Januari 2020

\section{PENDAHULUAN}

Anak bermain dengan media yang ada di sekitar mereka. Dengan semakin berkembangnya teknologi masa kini, permainan anak yang banyak digemari adalah virtual game (VG). VG memiliki kelebihan seperti bisa dimainkan kapan saja, ringkas, lebih memanjakan mata, lebih menarik, VG menantang sehingga membuat ketagihan. VG menjadi kebutuhan karena teman sejawat juga turut bermain. VG memiliki kelemahan seperti membuat interaksi sosial siswa menjadi kurang, siswa jadi kurang melatih emosi di depan manusia sesungguhnya. VG berbasis pada kompetensi individual. Anak bisa balapan meskipun mereka hanya duduk di ruang tamu. Dalam dunia maya anak mungkin bekerja secara berkelompok, namun anak hanya berinteraksi dengan layar gadgednya di dunia nyata dengan demikian interaksi sosial anak dengan teman sebayanya menjadi kurang (Giddings, 2016).

Di sisi lain, Dewantara (2011:241) menuliskan bahwa "Permainan anak itulah pendidikan" dan permainan anak dimasukkan ke sekolah sebagai kultur. Permainan tradisional Jawa seperti cublakcublak suweng dan dakon dapat digunakan untuk mendidik anak tentang pengertian menghitung (counting) dan memperkirakan (estimating). Permainan tradisional lainnya seperti benthik apat melatih kebugaran jasmani, menjernihkan penglihatan, kecekatan dan keberanian, berlatih untuk hidup teratur dan tertib.

Penelitian Sari, Agustini, \& KHB (2019) menunjukkan bahwa ada peningkatan hasil belajar pada subtema 3 Keseimbangan Ekosistem siswa Kelas V SD menggunakan permainan tradisional gobag sodor. Penelitian Hakim (2017) juga menunjukkan bahwa permanian gobag sodor dapat meningkatkan hasil belajar IPS siswa kelas IV SD. Penelitian Nataliya (2015) membuktikan bahwa permainan tradisional congklak/dakon di kelas III SD mampu meningkatkan kemampuan berhitung matematika. Hasil analisis Hanief \& Sugito (2015) bermain permainan tradisional seperti terompah panjang/bakiak dan bentengan dapat mengembangkan psikomotor anak yang dalam hal ini adalah gerak lokomotor dasar seperti berlari, berjalan, meloncat, menghindar, menangkap, menggiring, merayap dan lain-lain. Bahkan penelitian Susanti \& Harningtyas (2019) menunjukkan adanya peningkatan konsentrasi dan keterampilan sosial pada anak tunagrahita ringan melalui permainan 
tradisional engklek. Penelitian penelitian dari tahun 2015-2019 ini menunjukkan bahwa permainan tradisional dapat menunjang pendidikan SD di Indonesia.

Dalam dunia pendidikan SD, penguasaan kompetensi matematika menjadi penting. Matematika selalu digunakan dalam kehidupan sehari-hari. Matematika ada sejak dari bangun tidur, melihat waktu, mengukur kecepatan, memprediksi jarak dan seterusnya hingga kembali tidur. Matematika ada dimanamana, "it is experienced and practiced by every culture..." (Brandt \& Chernoff, 2015). Kendati demikian, matematika masih dianggap pelajaran yang sulit dimengerti karena matematika yang diajarkan tidak relevan dengan konteks siswa.

Untuk membuat konteks matematika menjadi lebih dekat dengan kehidupan siswa, ada sebuah pendekatan pembelajaran matematika yang dinamakan Matematika Realistik. Matematika Realistik adalah sebuah pendekatan pembelajaran matematika yang berkembang di Belanda. Realistics Mathematics Education (RME) yang dipelopori oleh Hans Freudenthal ini mengarahkan siswa untuk menemukan kembali matematika dengan cara mereka sendiri (Hadi, 2018:8). Konsepnya adalah penggunaan situasi yang bisa dibayangkan (imagined) oleh siswa (Wijaya, 2011:20).

Berdasarkan permasalahan pada latar belakang yang sudah disebutkan pada paragraf sebelumnya, pengembangan model pembelajaran berbasis permainan tradisional dengan pendekatan matematika realistic menjadi penting. Hal ini karena adanya inspirasi dari Ki Hadjar Dewantara. Pendidik Indonesia sebaiknya condong terhadap permainan tradisional. Karena permainan tradisional adalah salah satu bentuk budaya Bangsa Indonesia yang tidak dimiliki oleh bangsa lain. Meskipun demikian, bukan berarti pendidik menutup diri dari perkembangan teknologi. Penelitian ini adalah penelitian pengembangan yang bertujuan untuk mengembangkan langkah-langkah model pembelajaran Matematika SD menggunakan permainan tradisional dengan pendekatan matematika Realistik. Manfaat penelitian ini adalah memberikan alternatif pembelajaran pada matematika SD.

\section{KAJIAN PUSTAKA}

\section{Permainan Tradisional}

Di mata orang dewasa, "anak yang bermain" dianggap suatu hal yang tidak serius. Padahal bermain adalah pekerjaan penting yang dilakukan oleh anak-anak. Melalui bermain anak dapat menemukan kompetensi sosial, budaya, dan lingkungan sekitar mereka yang mungkin tidak diajarkan di ruang kelas. Memisahkan dunia belajar dan bermain anak adalah hal yang salah. Bermain bahkan dapat membantu pertumbuhan anak. Saat anak bermain, ada latihan motorik kasar dan halus seperti berlari, melompat, keseimbangan, koordinasi, ketahanan, kekuatan, kehati-hatian, ketelitian, dan lainnya. Bermain peran dapat melatih imajinasi anak, mereka bahkan bisa menerapkan konsep-konsep yang sudah mereka dapat seperti saat mereka bermain peran sebagai penjual dan pembeli. Bermain di luar ruangan bahkan mengajarkan konsep kebebasan, mengenal lingkungan sekitar mereka, mengenal budaya mereka (Wilson, 2018).

Pada usia 7-11 tahun, siswa SD berada pada tahap Concrete Operational dalam Teori belajar Piaget. Siswa dapat melakukan penalaran yang membutuhkan bukti konkret. Mereka dapat mengoperasikan benda konkret mereka bisa berimajinasi tetapi bukan untuk mengimajinasikan persamaan aljabar (Santrock, 2012:25). Piaget juga mengatakan bahwa seiring bertambahnya kompetensi anak untuk memahami objek, situasi dan dunia nyata, permainan itu akan hilang secara perlahan (Cohen, 2018:6). Bermain adalah menciptakan dunia yang lebih baik seperti mencerminkan dunia itu sendiri (Giddings, 2016), sehingga bermain ini adalah dunia yang konkret bagi seorang anak yang ada pada dunia sekolah dasar. Berdasarkan teori sociocultural cognitive Vygotsky, anak belajar dari orang-orang sekitarnya seperti belajar bahasa, sistem matematika, dan strategi untuk mengingat (Santrock, 2012:26).

Kebudayaan adalah segala sesuatu yang berkaitan dengan cipta, rasa, karsa, dan hasil karya masyarakat (Undang-Undang Republik Indonesia Nomor 5, 2017). Permaian tradisional merupakan warisan budaya takbenda, begitu juga dengan UNESCO mengangap permaian tradisional adalah Intangible Cultural Heritage. Budaya yang ada di sekitar anak adalah budaya dimana dia tinggal. Salah satu budaya yang ditinggalkan oleh leluhur di Indonesia adalah permainan tradisional sehingga, sudah seharusnya anak belajar budaya atau anak belajar melalui budaya yang ada melalui permaiann tradisional. Permainan tardisional Indonesia diantaranya adalah balap karung, bambu gila, bakiak, bebedilan, benteng, boy-boyan, cato / chees Karo dan Aceh, conglak, egrang, galah asin / gobak sodor, 
gasing, lompat tali / yeye, kelereng, dan banyak lainnya (Komara, 2018). Di Indonesia, negara yang memiliki ribuan budaya ini, permainan tradisional bisa saja berbeda nama dan berbeda aturan di setiap daerahnya. Berdasarkan teori belajar yang ada dan fakta bahwa Indonesia memiliki banyak budaya, anak di Indonesia akan mudah berkembang dengan budayanya.

\section{Matematika SD}

Pound \& Lee (2015:7-12) berpendapat bahwa dalam mengajarkan matematika membutuhkan mengajar yang kreatif, belajar yang kreatif, teman (partner) yang kreatif, dan matematika yang kreatif. Mengajar matematika yang kreatif adalah sebuah seni. Guru harus menggunakan kemampuannya untuk menyiapkan aktivitas yang menumbuhkan imajinasi, menciptakan pengalaman belajar, dan meningkatkan sumber daya. Belajar kreatif adalah kemampuan untuk menyimbolkan, mendukung, dan mewakili ide matematika. Teman yang kreatif adalah kondisi dimana belajar matematika didukung oleh lingkungan seperti, teman, guru, orang tua, masyarakat yang kreatif (komunitas belajar). Matematika bukanlah semata-mata tentang benar dan salah, matematika bahkan sering menggunakan tebakan dan intuisi. Matematika membutuhkan kemampuan untuk menggunakan simbol, gambar, diagram, dan model untuk berpikir. Matematika membutuhkan keterampilan untuk mengamati pola dan menyelesaikan masalah.

Dalam perkembangan K13 di Indonesia, pelajaran matematika SD untuk kelas 4-6 dipisah dari pembelajaran tematik karena karakter muatan pelajaran matematika berbeda dari muatan lain. Diperlukan kecakapan berpikir 4C yaitu Critical, Creative, Collaborative, dan Communicative dalam menguasai konsep matematika yang abstrak. Matematika dinilai sebagai muatan pelajaran yang membutuhkan pendalaman materi khusus dibanding muatan pelajaran lain di SD (Kemendikbud, 2016:2).

Tidak ada kriteria penilaian yang dikhususkan untuk pelajaran matematika di SD pada K-13, sehingga aspek yang dinilai dalam matematika adalah aspek yang sama dengan mupel yang lain yaitu aspek spiritual (Kompetensi Inti-1), sikap (KI-2), pengetahuan (KI-3), dan keterampilan (KI-4) (Kemendikbud, 2015). KI-1 dan KI-2 adalah aspek yang didapat siswa melalui indirect learning. KI-3 dan KI-4 matematika tertuang dalam poin-poin kompetensi dasar pada lampiran standar isi (Permendikbud No 21, 2016). Adapun garis besar materi matematika yang harus dikuasai anak SD adalah bilangan, geometri, dan statistika.

\section{Matematika Realistik}

Di Indonesia, Realistic Mathematics Education (RME) sering disebut dengan Pendidikan Matematika Realistik (PMR). RME dikembangkan oleh Institut Freudenthal di Belanda. Freudenthal sendiri adalah nama dari tokoh pendirinya yaitu Hans Freudenthal yang mendirikan institute tersebut pada tahun 1971. RME dikenalkan oleh RK Sembiring dan Pontas Hutagalung di Indonesia setelah beliau menghadiri International Conference on Mathematical Instruction, Shanghai tahun 1994. Ide tentang RME disambut baik di tanah air sehingga pada tahun 2001 RME di Indonesia dinamai Pendidikan Matematika Realistik Indonesia (PMRI) oleh para penggagasnya (Hadi, 2018).

Freudenthal (2006:2) lebih memilih pengertian matematika sebagai seni dari pada matematika sebagai sebuah ilmu. Bahkan Ferudenthal menekankan bahwa matematika adalah sebuah seni mental yang membuatnya lebih seperti keterampilan dari pada sebuah pengetahuan. Matematika adalah sebuah alat bukan suatu tujuan. Matematika lebih relevan karena kegunaannya dari pada kepastiannya. Bermatematika dibedakan menjadi dua yaitu matematika horisontal dan vertikal. Singkatnya, matematika horizontal adalah matematika yang berangkat dari dunia nyata ke dunia simbol, di sisi lain matematika vertikal berbicara tentang pengolahan simbol itu. Anak tidaklah mudah memahami konsep abstrak dari suatu simbol. Dalam de Lange (1996:57), Conceptual Mathematization (berkembangnya konsep dan ide matematika) berawal dari dunia nyata.

Dalam Wijaya (2011: 21-23), Trefferes mengungkapakan ada lima karakteristik RME yaitu penggunaan konteks, penggunaan model, pemanfaatan hasil konstruksi siswa, interaktivitas, dan keterkaitan. Konteks ini bukan berarti nyata secara harafiah tetapi konteks yang dekat dengan anak seperti permainan. Menghitung kecepatan laju mobil memang dibutuhkan secara nyata, tetapi akan lebih nyata bagi anak bila bentuknya adalah balapan lari. Model yang digunakan dalam matematisasi digunakan untuk mendekatkan siswa pada proses bermatematika secara vertikal seperti penggunaan block dienes setelah belajar berhitung menggunakan biji-biji pada dakon. Pemanfaatan konstruksi siswa 
diartikan sebagai penggunaan cara-cara bermatematika anak secara bebas. Interaktivitas adalah ketika siswa bisa mengembangkan kemampuan intrapersonalnya. Konsep konsep matematika akan saling berkaitan dalam RME.

RME mengajak pendidik menilai siswanya secara autentik, bukan semata mata pada kebenaran jawaban siswa dalam mengerjakan soal matematika tetapi lebihkepada porses berpikir mereka. De Lange (1996:89) mengatakan tujuan belajarnya adalah kemampuan menalar, komunikasi, dan perkembangan mental yang kritis dimana sekarang disebut dengan higher order thinking skills. Hal ini lah yang membuat kegiatan RME sesuai dengan konteks yang diketahui oleh siswa, bahasa yang sederhana, ditambah dengan media yang sesaui dengan konsep. Soal soal pada RME harus seimbang, bermakna, memiliki alternatif jawaban, terbuka, mengukur aspek yang dinilai, dan menekankan proses (Hadi, 2018).

Penelitian pengembangan ini ingin membawa sebuah pandangan baru tentang matematika yang hanya ada di Indonesia karena dikemas dalam permainan tradisional Indonesia. Permainan balogo, tasak, gatrik, dan benthik misalnya, itu adalah permainan yang mungkin hanya ada di Indonesia. Bila dengan permainan itu anak dapat belajar matematika, anak tidak perlu belajar jarak antar titik dalam buku tetapi bisa mengukur baik dengan satuan baku dan tidak baku dalam permainan gatrik. Anak tidak perlu takut dengan banyak soal angka-angka penjumlahan dan pengurangan bila bisa bermain dengan batu batu di permainan tasak. Hal ini dilakukan supaya anak bisa bermatematika sambil bermain sebelum mereka masuk ke dunia matematika yang abstrak.

\section{METODE PENELITIAN}

Penelitian Borg and Gall (1983) terdiri dari 10 tahap yaitu (1) penelitian dan studi pendahuluan, (2) perencanaan penelitian, (3) pengembangan produk awal, (4) uji lapangan terbatas, (5) revisi hasil uji lapangan terbatas, (6) uji lapangan lebih luas, (7) revisi hasil uji lapangan lebih luas, (8) uji efektifitas, (9) Revisi hasil uji efektifitas, dan (10) deseminasi dan sosialisasi produk akhir. Pada artikel ini hanya membahas empat tahap pertama dari model Borg and Gall yang sudah dimodifikasi dengan pendekatan Ki Hadjar Dewantara yaitu 3N (Niteni, Nirokke, dan Nambahi) (Wahyudi, Waluya, Suyitno, \& Isnarto, 2019; Rahayu, Purnami, \& Agustito, 2018; Wahyudi \& Winanto, 2018).

Penelitian ini dilakukan pada bulan Agustus 2019 di Salatiga dengan subjek 15 guru pengajar matematika SD di Salatiga yang diambil secara purposive sampling. Teknik pengumpulan datanya dengan menggunakan wawancara dan skala respons. Analisis data dilakukan secara kualitatif. Hasil penelitian ini diketegorisasikan dengan kategori pada tabel 1 Yang merupakan kategorisasi yang diadaptasi dari Mardapi (2012) dan Azwar (2017).

Tabel 1. Acuan Kategorisasi Skor dalam Empat Skala

\begin{tabular}{cl}
\hline Skor perolehan & \multicolumn{1}{c}{ Kategori } \\
\hline$X \geq \bar{X}+1 . S B x$ & Sangat Baik \\
\hline$X^{-}+1 . S B x>X \geq \bar{X}$ & Baik \\
\hline $\bar{X}>X \geq \bar{X}-1 . S B x$ & Buruk \\
\hline$X<\bar{X}-1 . S B x$ & Sangat Buruk \\
\hline
\end{tabular}

Keterangan:

$X=$ skor yang diperoleh

$\bar{X}=\frac{1}{2} \times($ skor maksimal ideal + skor minimal ideal $)$

$S B x=$ simpangan baku dari skor yang diperoleh

$S B x=\frac{1}{4} \times($ Skor maksimal ideal - Skor minimal ideal $)$

Skor maksimal ideal $=$ jumlah butir kriteria $\times$ skor tertinggi

Skor minimal ideal $=$ jumlah butir kriteria $\times$ skor terendah

Instrumen sekaligus produk yang sudah tercipta melalui uji pakar. Pakar yang bekerjasama dalam penelitian ini adalah Siska Dian A., M.Pd. (bidang keahlian Pendidikan Sekolah Dasar) dan Novita Ardiyansari, S.Pd., M.Sc. (bidang keahlian Sekolah Dasar dan Ketahanan Nasional). Instrumen yang digunakan sudah melalui proses validasi konten dan validitas dan reliabilitas dengan korelasi item $>0,30$. Adapun besarnya nilai reliabilitas Cronbach's Alpha instrumen yang digunakan adalah 0,819. 
Pengembangan Model Pembelajaran Matematika SD Berbasis Permainan Tradisional Indonesia dan

Pendekatan Matematika Realistik (Yohana Setiawan)

\section{HASIL PENELITIAN DAN PEMBAHASAN}

\section{Penelitian dan Studi Pendahuluan}

Pada tahap penelitian dan studi pendahuluan dilakukan analisis kepustakaan yang menghasilkan bahwa sudah ada penelitian mengenai permainan tradisional yang dapat meningkatkan kemampuan anak, tidak hanya matematika saja namun banyak aspek yang bisa dikembangkan melalui permainan tradisional. Selain itu telah dilakukan wawancara terhadap 15 guru matematika SD di Salatiga mengenai ide permainan tradisional yang digabung dengan pendekatan RME.

Karakteristik dari subjek wawancara adalah 33,3\% adalah guru pengajar matematika SD yang berpengalaman mengajar kurang dari 5 tahun dan 66,7\% lainya adalah guru dengan pengalaman mengajar lebih dari 15 tahun. Terdapat 6,7\% guru pernah mengaplikasikan PMRI di kelas dengan demikian sebanyak 93,3\% guru belum pernah menggunakan PMRI. Meskipun demikian 93,3\% guru memberikan pendapat positif mengenai menggabungan PMRI dengan permainan tradisional. Guru mengatakan bahwa ide yang ditawarkan adalah ide yang bagus. Belajar dan bermain dapat membuat siswa berminat, termotivasi belajarnya. Ada guru yang berpendapat bawa ide ini dapat digunakan untuk melestarikan budaya dan peserta didik dapat belajar tidak hanya matematika tetapi keterampilan lainnya. Dari hasil wawancara itu juga didapatkan bahwa 6,7\% guru berpendapat bahwa penggunaan permainan tradisional yang digunakan dalam pembelajaran malah membuat anak terlalu asyik bermain dari pada belajar.

\section{Perencanaan Penelitian}

Dalam penelitian ini ada tiga tahap yang harus dilalui oleh pengembang produk yaitu tahap Niteni, Nirokke, dan Nambahi (Rahayu, Purnami, \& Agustito, 2018). Pada tahap Niteni pengembang harus menangkap makna dari matematika itu sendiri, menangkap makna dari RME, dan menangkap makna dari permainan tradisional yang mereka kenal. Tahap Nirokke adalah tahap dimana pengembang meniru frame work dari beberapa contoh RME yang terdapat pada modul PMRI, SEAMEO-QITEP (2010). Pada akhirnya pengembang harus melakukan sebuah inovasi dengan menggabungkan permainan tradisional sebagai bagian dari proses Nambahi. Produk yang dihasilkan kemudian dinilai oleh 15 guru SD yang mengajar matematika.

Pada proses Nambahi, produk yang dihasilkan harus melalui diskusi bersama antarpengembang produk lain yaitu mahasiswa PGSD UKSW yang ikut matakuliah Matematika Realistik angkatan 2016 kelas D, E, dan F. Pada proses diskusi, setiap pengembang produk diharuskan memberikan gambaran jelas mengenai cara bermain permainan tradisional itu bahkan mempraktikkannya. Hasil dari diskusi ini adalah masukkan mengenai manajemen kelas, persiapan ruang kelas, media, dan efisiensi waktu.

\section{Pengembangan Produk Awal}

Pengembangan produk diawali dengan memperkenalkan garis besar RME/PMRI seperti PMRI berbasis pada kondisi yang real/nyata bagi siswa, RME tidak menekankan pada hasil saja tetapi lebih kepada proses berpikir siswa sehingga kemungkinan jawaban yang dihaslikan tidak hanya satu cara melainkan ada banyak cara sesuai penalaran siswa. LKPD pada RME adalah soal yang memberi stimulus siswa untuk berproses matematika. Soal yang dimaksudkan adalah soal yang kontekstual yang dapat dinalar atau media yang dimanipulasi adalah media di sekitar siswa seperti, menggunakan gambar kawanan kerbau untuk belajar statistik, menggunakan denah tempat parkir untuk belajar persentase, menggunakan maze untuk membandingkan jarak terdekat dan terjauh, dan soal lainnya.

Selanjutnya, dilakukan kegiatan seperti yang dirancang oleh PMRI SEAMEO-QITEP (2010), dengan tujuan agar lebih memaknai RME sebagai kegiatan yang berbeda dari pendekatan belajar matematika lain. Kegiatan yang dilakukan diantaranya adalah melakukan proses berhitung menggunakan "garis bilangan" yang terbuat dari pola tertentu, misalnya pola lingkaran hitam-putih 22 dan 5-5, lalu membandingkan mana yang lebih mudah menempatkan bilangan. Kegiatan lainya adalah seperti mengukur menggunakan manik-manik/ sedotan yang sudah dipotong dan mengukur benda menggunakan penggaris yang sudah patah. Ada juga kegiatan memprediksi luas suatu bangun, pencerminan bangun, dan statistika.

Langkah selanjutnya adalah melakukan mencampuran antara permaian tradisional dengan matematika realistik yang dimulai dengan memilih permainan tradisional dan dilanjutkan dengan 
memilih KD matematika yang dapat diaplikasikan dengan permainan tradisional tersebut. Beberapa hasil dari pengembangan produknya yaitu sebagai berikut.

1. Permainan balap karung untuk materi kecepatan (perbandingan jarak dan waktu) untuk kelas V.

2. Permainan gatrik untuk materi statistika kelas V.

3. Permainan gobag sodor untuk materi garis sejajar, berpotongan, dan berhimpit untuk kelas IV.

4. Permainan tasak untuk bilangan prima kelas IV.

5. Permainan balogo untuk operasi hitung kelas II.

6. Permainan engklek untuk materi bangun datar untuk kelas II.

Sebelum dilakukannya uji lapangan terbatas, produk yang dihasilkan dinilai oleh dua pakar. Kedua pakar berpendapat bahwa inovasi pembelajaran yang student centered akan memberikan kontribusi dalam rangka pengembangan ranah kognitif, afektif, dan psikomotor siswa. Dari 15 RPP dan LKPD yang dinilai, 20\% permainan tradisional yang dipilih masih belum sesuai dengan KD Matematika. $80 \%$ produk lainnya dinilai sangat baik karena muncul ide-ide pembelajaran matematika baru. Muncul kekhawatiran bahwa ide baik ini akan sulit diterapkan bila masih menggunakan kurikulum tematik mengingat alokasi waktu belajar matematika yang berbenturan dengan mupel lain, tetapi tidak menutup kemungkinan justru menjadi tema baru yang menarik untuk belajar kekayaan nusantara. Adapun saran yang diberikan oleh kedua pakar adalah perlunya pengembang produk dalam memperhatikan konsep matematika, agar soal-soal pada LKPD tidak hanya soal evaluasi C1 melainkan soal HOTS.

Adapun hasil dari diskusi dengan ahli adalah penerapan berbagai jenis permainan tradisional dalam mata pelajaran matematika diharapkan mampu menjadi sarana efektif dalam melaksanakan pembelajaran yang menyenangkan. Selain menyenangkan, kolaborasi permainan tradisional dengan Matematika Realistik berpotensi untuk meningkatkan aspek-aspek perkembangan siswa dengan cara yang rekreatif. Pemanfaatan permainan tradisional akan membekali siswa untuk mencintai produk budayanya dan dapat ditindaklanjuti dengan melestarikan budayanya.

\section{Uji lapangan terbatas}

Uji lapangan terbatas dilakukan dengan meminta respons kepada guru-guru terhadap produk yang telah dibuat. Produk berupa RPP yang disertai rundown dan aturan permainan yang sebagian sudah dimodivikasi guna pembelajaran matematika.

Tabel 2. Acuan Kategorisasi Skor Skala Respons Guru

\begin{tabular}{cl}
\hline Skor perolehan & \multicolumn{1}{c}{ Kategori } \\
\hline$X \geq 45$ & Sangat Baik \\
\hline $45>X \geq 30$ & Baik \\
\hline $30>X \geq 15$ & Buruk \\
\hline$X<15$ & Sangat Buruk \\
\hline
\end{tabular}

Tabel 2 adalah acuan kategorisasi skor berdasarkan tabel 1. Secara keseluruhan respons guru terhadap produk yang berupa rancangan pembelajaran yang dilengkapi dengan LKPD dan aturan permainan dengan pendekatan PMRI dan permainan tradisional adalah Sangat Baik dapat dilihat pada tabel 3. Berdasarkan Trefferes (dalam Wijaya, 2011) produk sudah menerapkan karakteristik RME yaitu pertama penggunaan konteks yang dalam hal ini adalah permainan tradisional. Penggunaan model matematika juga dilakukan di dalam produk seperti, pemanfaatan papan geometri dalam permainan engklek yang sudah dimodifikasi. Hasil respons guru terhadap kesesuaian PMRI dengan pemilihan permainan tradisional dan KD matematika SD adalah Sangat Baik. 
Pengembangan Model Pembelajaran Matematika SD Berbasis Permainan Tradisional Indonesia dan

Pendekatan Matematika Realistik (Yohana Setiawan)

Tabel 3. Hasil Respons Guru

\begin{tabular}{llc}
\hline \multicolumn{1}{c}{ Aspek } & Perolehan skor & Kategori \\
\hline $\begin{array}{l}\text { Kesesuaian pemilihan permainan tradisional dengan KD } \\
\text { matematika }\end{array}$ & 51 & Sangat Baik \\
\hline Pendekatan PMRI dengan permainan tradisional yang dipilih & 53 & Sangat Baik \\
\hline Kesesuaian LKPD dengan indikator & 45 & Sangat Baik \\
\hline Kesesuaian LKPD dengan PMRI & 48 & Sangat Baik \\
\hline
\end{tabular}

Karakteristik ketiga dalam RME adalah pemanfaatan hasil konstruksi siswa yang bisa dilihat pada LKPD. Respon guru terhadap kesesuaian LKPD terhadap indikator dan pendekatan PMRI adalah Sangat Baik. LKPD dikembangkan dengan prinsip memiliki alternatif jawaban, terbuka, mengukur aspek yang dinilai, dan menekankan proses (Hadi, 2018). Karakterisik RME yang ketiga adalah interaktivitas. Interekativitas adalah bagaimana kegiatan di kelas mampu meningkatkan keterampilan intrapersonal peserta didik. Dengan bermain dengan teman, siswa dapat mengenal budaya, dan lingkungan sekitar (Wilson, 2018).

Keterkaitan adalah karakteristik kelima RME. Siswa dituntut untuk dapat melakukan intertwining (seperti menganyam/menjalin) konsep konsep matematika. Permainan tradisional gobag sodor misalnya, dapat melatih siswa untuk menerapkan konsep garis, bisa juga konsep operasi hitung bilangan, bisa juga untuk belajar statistik, bahkan bisa untuk belajar apa itu kecepatan. Keunggulan dari permainan anak adalah dapat melatih psikomotor seperti kebugaran jasmani dan afektif seperti kecekatan dan keberanian, berlatih untuk hidup teratur dan tertib (Dewantara, 2011).

Beberapa kelemahan yang ditemukan dalam pengembangan produk awal dan juga pada uji lapangan terbatas adalah diperlukan sebuah persiapan yang sangat matang supaya siswa dapat mencapai tujuan pembelajaran. Bila tidak dipersiapkan dengan matang, malah menyulitkan guru. Ada pula yang berpendapat bahwa permainan tradisional seperti benthik bisa membahayakan siswa, karena ranting yang dipukul bila mengenai tubuh siswa, siswa bisa terluka. Permainan tradisional yang dilakukan secara beregu misalnya bermain kelereng yang dilombakan antar regu yang dilakukan secara bersamaan dapat membuat guru kesulitan dalam mengamati/menilai siswa.

Dari penelitian ini dapat dirumuskan sebuah langkah untuk membuat rencana pembelajaran matematika SD dengan permainan tradisional yang dikembangkan dengan pendekatan RME. Langkah langkahnya adalah sebagai berikut. Langkah pertama adalah menentukan KD dan permainan tradisional yang sesuai dengan KD yang dipilih. Langkah kedua adalah menetukan indikator pencapaian yang nantinya sebagai acuan membuat LKPD. Langkah ketiga adalah membuat aturan permainan yang sudah disesuaikan dengan RME. Prinsip pembuatan rencana pembelajarannya adalah permainan yang dipilih adalah permainan tradisional Indonesia, menggunakan model (media manipulatif) matematika, penggunaan LKPD yang terbuka terhadap jawaban siswa yang beragam, sesuai indikator, dan menekankan proses berpikir matematika (Hadi, 2018; Dewantara, 2011; Wijaya, 2011;).

Apabila merasa kesulitan dalam pembuatan rencana pembelajaran tersebut, dapat dilakukan dengan 3N, Niteni, Nirokke, dan Nambahi (Wahyudi, Waluya, Suyitno, \& Isnarto, 2019; Rahayu, Purnami, \& Agustito, 2018; Wahyudi \& Winanto, 2018). Pada bagian Niteni dilakukan telaah mengenai karakteristik dari permainan tradisional tersebut, karakteristik RME, dan karakteristik Kompetensi Dasar Matematika SD. Pada tahap Nirokke dilakukan komparasi dengan rencana pembelajaran versi RME yang dapat dilihat pada Hadi (2011). Penggabungan antara permainan tradisional dengan RME dapat dilakukan pada tahap Nambahi.

\section{SIMPULAN DAN SARAN}

Penelitian ini menghasilkan produk berupa rancangan pembelajaran matematika atau secara resmi biasa disebut Rencana Pelaksanaan Pembelajaran (RPP). Pada rancangan ini dilengkapi dengan LKPD dan aturan permainan yang telah dimodifikasi dengan RME. Produk penelitian ini disambut baik oleh guru guru SD yang mengajar matematika. Ide yang ditawarkan produk ini adalah penggabungan permainan tradisional Indonesia dengan RME. Permainan tradisional dipilih karena terinspirasi dari cita-cita Ki Hadjar Dewantara, Bapak Pendidikan Indonesia. Beliau mengatakan bahwa diluar memang ada Froebel and Montessori tapi di Indonesia ada permainan tradisional. RME dipilih karena matematika bagi siswa SD adalah matematika yang nyata dan berfungsi di kehidupan anak. 
Hasil dari penelitian ini bukan menggiring opini pendidik untuk meniadakan kegiatan anak bermain virtual games tetapi justru ingin mengajak pendidik mengembangkan pendidikan blended learning. Siswa dapat tetap bermain dan mengenal budaya Indonesia melalui permainan tradisional dan juga mengajak anak belajar matematika yang lebih aplikatif.

Hal menarik yang bisa dikembangkan lebih lanjut dari penelitian ini adalah mengembangkan permainan tradisional dalam bentuk video game seperti pengembangan game conglak oleh Malaysia (ChePa, Alwi, Din, \& Mohammad, 2014). Sayangnya, game ini bukan untuk belajar matematika tetapi hanya sebatas untuk melestarikan budaya Malaysia. Berdasarkan Sanaki (dalam Nomleni \& Manu, 2018:220), media audio visual menyajikan objek belajar yang konkret atau mengandung pesan pembelajaran realistik. Audio visual dalam hal ini adalah video game sangat dekat dengan siswa atau sesuai dengan dunia anak. Bila video game digunakan untuk mengurangi kejenuhan belajar matematika, maka hal ini akan sangat baik untuk belajar anak. Disisi lain memang psikomotor anak khususnya motorik kasar anak tidak akan banyak bergerak dibanding dengan permainan tradisional di dunia nyata.

\section{UCAPAN TERIMAKASIH}

Memberikan apresiasi kepada mahasiswa PGSD, FKIP, UKSW pada matakuliah Matematika Realistik angkatan 2016 kelas D, E, dan F, guru-guru matematika SD, Siska Dian A., M.Pd., dan Novita Ardiyansari, S.Pd., M.Sc. yang sudah terlibat dalam penelitian ini.

\section{DAFTAR PUSTAKA}

Azwar, S. (2017). Metode penelitian. Yogyakarta: Pustaka Pelajar.

Borg, W. R., \& Gall, M. D. (1983). Educational research: an introduction. New York: Longman.

Brandt, A., \& Chernoff, E. J. (2015). The importance of ethnomathematics in the math class. Ohio Journal of School Mathematics, no. 71 (2015), 31-36.

ChePa, N., Alwi, A., Din, A. M., \& Mohammad, S. (2014). Digitizing Malaysian Traditional Game: eCongkak. In Knowledge Management International Conference (KMICe), Malaysia.

Cohen, D. (2018). The development of play. Routledge.

De Lange J. (1996) Using and Applying Mathematics in Education. In: Bishop A.J., Clements K., Keitel C., Kilpatrick J., Laborde C. (eds) International Handbook of Mathematics Education. Kluwer International Handbooks of Education, vol 4. Springer, Dordrecht

Dewantara, K. H. (2011). Karya K.H Dewantara bagian pertama Pendidikan, Yogyakarta: Majelis Luhur Persatuan Tamansiswa

Freudenthal, H. (2006). Revisiting Mathematics Education: China Lectures. Kluwer: Dordrecht/Boston/London.

Giddings, S. (2016). Gameworlds: virtual media and childrens everyday play. London: Bloomsbury.

Gerakan Literasi Nasional. (2017, October 12). Warisan Budaya Tak Benda. Retrieved December 1, 2019, from https://gln.kemdikbud.go.id/glnsite/formulir-warisan-budaya-tak-benda/.

Hadi, S. (2018). Pendidikan matematika realistik. PT RajaGrafindo Persada. ISBN 978-602-425-0812

Hakim, A. R. (2017). Efektivitas Permainan Tradisional Gobag Sodor untuk Pembelajaran IPS Kelas IV Sekolah Dasar. Jurnal Bidang Pendidikan Dasar, 1(1), 33-39.

Hanief, Y. N., \& Sugito, S. (2015). Membentuk gerak dasar pada siswa sekolah dasar melalui permainan tradisional. Jurnal SPORTIF: Jurnal Penelitian Pembelajaran, 1(1), 100-113.

Kemendikbud. (2015). Panduan penilaian untuk sekolah dasar (SD). Retrieved from https://akhmadsudrajat.files.wordpress.com/2015/12/panduan-penilaian-untuk-sekolah-dasarsd.pdf 
Pengembangan Model Pembelajaran Matematika SD Berbasis Permainan Tradisional Indonesia dan

Pendekatan Matematika Realistik (Yohana Setiawan)

Kemendikbud. (2016). Panduan pembelajaran matematika dan Pendidikan Jasmani, Olahraga dan Kesehatan (PJOK). Retrieved from https://drive.google.com/file/d/1db3rXNfsrB0RxFQZdmSp6qmsUzeCj3m-/view

Komara, E. (2018). Traditional Game Sports and the Conservation of Local Culture. From Many to One: Sustaining Our Spirit of Recreation, 75.

Laurens, T., Batlolona, F. A., Batlolona, J. R., \& Leasa, M. (2018). How does realistic mathematics education (RME) improve students' mathematics cognitive achievement. Eurasia Journal of Mathematics, Science and Technology Education, 14(2), 569-578.

Mardapi, Djemari. (2012). Pengukuran penilaian \& evaluasi pendidikan. Yogyakarta: Nuha Litera.

Medina, C. L. \& Wohlwend, K. E. (2014). Literacy, play and globalization:converging imaginaries in children's critical and cultural performances. New York: Routledge.

Mutiah, D. (2010). Psikologi bermain anak usia dini, Jakarta: Kencana

Nomleni, F. T., \& Manu, T. S. N. (2018). Pengembangan media audio visual dan alat peraga dalam meningkatkan pemahaman konsep dan pemecahan masalah. Scholaria: Jurnal Pendidikan dan Kebudayaan, 8(3), 219-230.

Permendikbud. (2016). Peraturan Menteri Pendidikan dan Kebudayaan Nomor 21 Tahun 2016 Tentang Standar Isi Pendidikan Dasar dan Menengah. Retrieved from https://bsnp-indonesia.org/wpcontent/uploads/2009/06/Permendikbud_Tahun2016_Nomor021_Lampiran.pdf

Pound, L., \& Lee, T. (2015). Teaching mathematics creatively. London: Routledge.

Rahayu, I., Purnami. A. S., \& Agustito, D. (2018). Penerapan konsep 3N (Niteni, Nirokke, Nambahi) untuk meningkatkan motivasi belajar matematika siswa. dalam Prosiding Seminar Nasional Pendidikan Matematika Etnomatnesia.

Sanger, J., Wilson, J., Davies, B., \& Whittaker, R. (2019). Young children, videos and computer games: Issues for teachers and parents. Routledge.

Santrock, J. W. (2012). Life-Span development. New York: McGraw-Hill.

Sari, N. Y., Agustini, F., \& KHB, M. A. (2019). Efektivitas Permainan Tradisional Gobag Sodor Terhadap Hasil Belajar Subtema 3 Keseimbangan Ekosistem. Indonesian Journal Of Educational Research and Review, 2(1).

Sembiring, R. K., Hadi, S., \& Dolk, M. (2008). Reforming mathematics learning in Indonesian classrooms through RME. ZDM, 40(6), 927-939.

Suprayitno, S. (2017). Peran permainan tradisional dalam membantu pertumbuhan dan perkembangan gerak anak secara menyeluruh. Jurnal ilmu keolahragaan, 13(2), 7-15.

Susanti, N., \& Harningtyas, S. (2019). EFEKTIFITAS PERMAINAN TRADISIONAL ENGKLEK TERHADAP PENINGKATAN KONSENTRASI DAN KETRAMPILAN SOSIAL PADA ANAK TUNAGRAHITA RINGAN DI SDLB NEGERI KEDUNGKANDANG KOTA MALANG. BRAVO'S (Jurnal Prodi Pendidikan Jasmani \& Kesehatan), 7(3), 115-121.

Tanjung, H. S., \& Nababan, S. A. (2018). Pengaruh penggunaan metode pembelajaran bermain terhadap hasil belajar matematika siswa materi pokok pecahan di kelas III SD Negeri 200407 Hutapadang. Bina Gogik: Jurnal Ilmiah Pendidikan Guru Sekolah Dasar, 3(1).

Undang-Undang Republik Indonesia Nomor 5 Tahun 2017 Tentang Pemajuan Kebudayaan. https://warisanbudaya.kemdikbud.go.id/

Van den Heuvel-Panhuizen, M., \& Drijvers, P. (2014). Realistic mathematics education. Encyclopedia of mathematics education, 521-525.

Wahyudi, W., Waluya, B., Suyitno, H., \& Isnarto, I. (2019). The Use Of 3CM (Cool-Critical-Creative- 
Wahyudi, W., Waluya, B., Suyitno, H., \& Isnarto, I. (2019). The Use Of 3CM (Cool-Critical-CreativeMeaningful) Model In Blended Learning To Improve Creative Thinking Ability In Solving Mathematics Problem. Journal of Educational Science and Technology (EST), 5(1), 26-38.

Wahyudi, W., \& Winanto, A. (2018). Development of Project-based Blended Learning (PjB2L) Model To Increase Pre-Service Primary Teacher Creativity. Journal of Educational Science and Technology (EST), 4(2), 91-102.

Wijaya, A. (2011). Pendidikan matematika realistik: Suatu alternatif pendekatan pembelajaran matematika. Yogyakarta: Graha Ilmu.

Wilson, R. A. (2018). Nature and young children: encouraging creative play and learning in natural environments. New York, NY: Routledge. 